\title{
CONTRIBUIÇÕES DOS JOGOS E BRINCADEIRAS NA EDUCAÇÃO INFANTIL DO CAMPO
}

\author{
Luciana Freitas de Oliveira Almeida ${ }^{1}$; Elizabete Pereira Barbosa ${ }^{2}$; \\ 1. Bolsista PROBIC/UEFS, Graduando em Educação Física, Universidade Estadual de Feira de Santana, e-mail: \\ luh feira@hotmail.com \\ 2. Orientadora, Departamento de Educação, Universidade Estadual de Feira de Santana, e-mail: \\ beteuefs@gmail.com
}

PALAVRAS-CHAVE: Educação do Campo, Educação Infantil, Jogos e brincadeiras

\section{INTRODUÇÃO}

O presente texto é resultado do plano de trabalho intitulado "Contribuições dos jogos e brincadeiras na Educação Infantil do Campo", que tem como objetivo fazer uma análise sobre as contribuições dos jogos e brincadeiras na Educação Infantil do Campo de uma escola municipal, de um distrito de Feira de Santana. Trata-se de um recorte do projeto de pesquisa maior, vinculado ao Centro de Estudo e Documentação em Educação (CEDE) intitulado: "Educação infantil na zona rural: caracterização e análise do cenário de implementação das políticas de educação do campo no município de Feira de Santana".

Este trabalho justifica-se porque os jogos e brincadeiras se fazem necessários para o desenvolvimento da criança na Educação Infantil do Campo e não foi encontrada na literatura pesquisada, uma investigação sobre esse tema com foco na escola do campo. Neste cenário a questão de pesquisa que norteia é qual a contribuição dos jogos e brincadeiras na Educação Infantil do Campo?

Ao pensar sobre o lugar que os jogos e brincadeiras ocupam dentro da Educação Infantil do Campo, cabe retomar o ordenamento jurídico. A Lei de Diretrizes e Bases da Educação Nacional, LDB 9.394/96, estabelece no Art. 28, a necessidade de adaptações na oferta de educação básica para a população rural, considerando os conteúdos, metodologias, organização escolar própria, adequação do calendário e a organização do trabalho pedagógico à natureza do trabalho na zona rural.

Diante do exposto e compreendendo a importância do direito a educação para todos os indivíduos do campo, em particular as crianças, é necessário salientar que a Educação Infantil do Campo deve ser considerada com todas as suas particularidades, ressaltando a importância da permanência na escola e as aulas precisam envolver as crianças com o prazer e o encanto em aprender.

Nesse sentido, no artigo 29, da mesma Lei 9.394/96 no que diz respeito à Educação Infantil fica estabelecido que a Educação Infantil, primeira etapa da educação básica, tem como finalidade o desenvolvimento integral da criança, em seus aspectos físico, psicológico, intelectual e social, complementando a ação da família e da comunidade (BRASIL, 1996). As afirmações consideradas nestes artigos fomentaram a necessidade de ampliar o estudo em torno do tema Educação Infantil do Campo e suas relações com a Educação Física. Isso porque essa mesma lei no parágrafo $3^{\circ}$, do artigo 26 institui que a Educação Física, integrada a proposta pedagógica da escola, é componente curricular obrigatório da educação básica (BRASIL, 1996)

\section{MATERIAL E MÉTODOS OU METODOLOGIA (ou equivalente)}

Para analisar a contribuição dos jogos e brincadeiras na Educação Infantil do Campo foi utilizada a abordagem qualitativa de pesquisa (ANDRÉ, LUDKE, 1986) em conformidade com o projeto principal que originou este plano de trabalho. Sabendo que Feira de Santana tem 8 distritos, foi selecionado apenas um destes, o distrito de Jaguara. Em seguida foi 
realizado uma caracterização dos aspectos administrativos e pedagógicos, após este processo foram feitas entrevistas semiestruturadas com os dois professores que aceitaram participar. Os professores se disponibilizaram a participar e assinaram devidamente o Termo de Consentimento Livre e Esclarecido (TCLE), a partir das entrevistas foram feitas as transcrições das narrativas dos professores e posteriormente a análise de suas falas.

Durante o período de revisão sobre o tema proposto no plano de trabalho, fez-se um levantamento de dados no Portal do MEC (Ministério de Educação) onde foram encontrados textos, ordenamento jurídico no que tange a Educação Infantil, como: as Diretrizes Curriculares para Educação Infantil, os volumes 1 e 2 dos Parâmetros Nacionais de Qualidade para a Educação Infantil e os Parâmetros Básicos de Infraestrutura para Instituições de Educação Infantil e, no que diz respeito ao jogos e brincadeiras, foi encontrado o livro e o documentário do Território do Brincar : diálogos com escolas e um documento técnico de brinquedos e brincadeiras com a finalidade de orientar os professores.

O texto dialoga com as produções de autores como: Caldart (2009); Friedmann (1996); Freire \& Scaglia (2003); Darido \& Rangel (2005); Silva (2005); Saviani (2016), que debatem sobre as temáticas Educação do Campo, Educação Infantil, Jogos e brincadeiras. Foram utilizados também o ordenamento jurídico e os documentos oficiais tais como: Lei de Diretrizes e Bases da Educação $n^{\circ}$ 9.394/96 (BRASIL 1996), Portal do Ministério da Educação e Portaria 09/2017 (FEIRA DE SANTANA)

\section{RESULTADOS E/OU DISCUSSÃO (ou Análise e discussão dos resultados)}

Para Caldart (2009), a Educação do Campo nasce como uma crítica à realidade a educação brasileira, em particular, à respeito ao tipo de educação do povo que trabalha e vive no/do campo.

\footnotetext{
Uma crítica prática: lutas sociais pelo direito à educação, configuradas desde a realidade da luta pela terra, pelo trabalho, pela igualdade social, por condições de uma vida digna de seres humanos no lugar em que ela aconteça. É fundamental considerar para compreensão da constituição histórica da Educação do campo o seu vínculo de origem com as lutas por educação nas áreas de reforma agrária e como, especialmente neste vínculo, a Educação do campo não nasceu como uma crítica apenas de denúncia: já surgiu como contraponto de práticas, construção de alternativas, de políticas, ou seja, como crítica projetiva de transformações. (CALDART, p. 39)
}

A Educação do Campo surgiu e se fortaleceu através das luta dos movimentos sociais do campo, em particular o MST, para que o trabalhador do campo tenha acesso ao conhecimento historicamente acumulado e produzido na sociedade e problematizá-los para se colocar como sujeitos críticos. Se posicionando firme, agindo e tento uma característica própria, a Educação do Campo não desiste da universalidade, muito pelo contrário, luta para sua inclusão nela.

Neste sentido, é preciso que desde a educação infantil a criança seja orientada a ter um posicionamento crítico, para que fortaleça sua identidade como sujeito pertencente ao campo. Baseando-se na pedagogia histórico-crítica que inicia-se pela prática social, com alunos e professores, onde se estabelece diretamente com o cotidiano do aluno, identificando o problema para assim o professor preparar os materiais teóricos e práticos para o seu entendimento e solução através da instrumentação, sistematizar o conhecimento e através da catarse, o aluno fará uma síntese do que foi aprendido por ele, para que ao final seja retornado a prática social. Saviani (2016) esclarece dizendo que a pedagogia histórico-crítica é entendida como mediadora da prática social global.

Sabe-se que a escola tem um papel importantíssimo na formação da criança, e que desde a na Educação Infantil fica claro o desejo da criança em conhecer os fenômenos que as 
cercam diante de suas manifestações, principalmente, em coisas desconhecidas. Sendo o jogo uma invenção do homem, um ato de intencional de representações de ações e reações da realidade, que resultam na forma criativa e imaginária de modificar a situação presente, se constitui como um importante instrumento para contribuir para o desenvolvimento infantil. "O jogo apresenta-se como elemento básico para a mudança das necessidades e da consciência". (COLETIVO DE AUTORES,1992, p.46). O jogo possibilita uma liberdade de ação e invenção e o que parece ser difícil, torna-se fácil através dele, são essenciais para o desenvolvimento da criança proporcionando simulações lúdicas da realidade.

$\mathrm{Na}$ escola investigada, tem dois professores de Educação Física que atuam durante a reserva de carga horária dos professores de acordo com o que estabelece a Portaria 09/2017(FEIRA DE SANTANA, 2017). Para tanto a LDB 9394/96 no parágrafo $3^{\circ}$, do artigo 26, institui que a Educação Física, integrada a proposta pedagógica da escola, é componente curricular obrigatório da educação básica (BRASIL, 1996). Os jogos e brincadeiras são trabalhados sistematicamente, com dia e carga horárias reservados para tal proposta, o professor A esclarece que sua atividade é como professor reserva de carga horária, estabelecidos na Portaria 09/2017, e como tal é feita uma vez por semana, e que em sua aula gosta de dedicar pelo menos uma hora para trabalhar com jogos e brincadeiras. Já para o professor B, em especial para o grupo 05 no qual ele trabalha, a aula é totalmente dedicada para jogos e brincadeiras.

Percebeu-se nas falas dos professores A e B que utilizam estratégias metodológicas diferentes, um desenvolve suas aulas mais voltadas para a questão motora, já o outro voltado mais para questão da interatividade, utilizando-se dos jogos e brincadeiras. Além disso, o professor B ressalta que além das atividades diárias, desenvolve projetos na escola voltados para a valorização do distrito. Não se trata apenas do conteúdo específico da Educação Física, mas a valorização da identidade das crianças do campo, como por exemplo o projeto "Feira quero te ver" e o "Horta escolar." Também foi questionado se trabalha com jogos e brincadeiras nas suas aulas e como organiza, o professor A diz que trabalha muito, pois os jogos e brincadeiras traz muito desenvolvimento às crianças, além de acalmá-los. Já o professor B, diz que antes de iniciar a aula apresenta o conteúdo, mostra aos alunos, esclarecendo o objetivo da brincadeira. Darido e Rangel (2005) e o Coletivo de Autores (1992) compartilham da mesma ideia, que os jogos e brincadeiras são vistos como sinônimos, compreendidos indistintamente. O jogo possui uma liberdade de ação e invenção, o que parece ser difícil torna-se fácil através do jogo. Defendem que os jogos e brincadeiras são essenciais para o desenvolvimento da criança.

Não é apenas trabalhar com jogos e brincadeiras sem intencionalidade é importante desenvolver nos alunos a consciência crítica a respeito do que está sendo apresentado na aula, para que o aluno entenda o porquê de tal atividade, qual o objetivo e como pode resolver tais jogos e brincadeiras, desenvolvendo o raciocínio lógico, a autonomia, criticidade, criatividade, responsabilidade, interação e cooperação.

Segundo Friedmann (1996) o jogo é mais que o simples ato de brincar. Através dele a criança se comunica com o mundo e também está se expressando. Nesse sentido a importância do jogo vai para além do simples ato do brincar por brincar, e sim, através do jogo observar as comunicações das crianças expressando a realidade por eles observada nesse momento do brincar. Ainda, segundo Friedmann(1996), a educação deve instrumentalizar as crianças de forma a tornar possível a construção de sua autonomia, criticidade, criatividade, responsabilidade e cooperação.

Portanto, os jogos e brincadeiras contribuem significativamente para o desenvolvimento da criança e sua inserção na vida social. Transmitem cultura, história, desenvolvem habilidades motoras complexas. Vistos como sinônimos, os jogos e brincadeiras contribuem para a criança desenvolver a sua identidade e sua autonomia, além de os jogos e 
brincadeiras são conhecidas pelas crianças, não exigem espaço ou material aprimorado; flexibilidade nas regras; podem ser praticados em qualquer faixa etária, podem representar papéis sociais, estabelece relações com outras crianças que é o princípio da interação.

\section{CONSIDERAÇÕES FINAIS (ou Conclusão)}

Diante do exposto, ficou evidente que ainda existe a necessidade em pesquisar e discutir sobre os jogos e brincadeiras na Educação Infantil do Campo e sobre a presença do professor de Educação Física no ambiente escolar para trabalhar seu conteúdo, pois a produção na literatura sobre a temática é limitada. Os achados do estudo durante a revisão/levantamento bibliográfico revelam que a utilização dos jogos e brincadeiras nas aulas da Educação Infantil do Campo contribuem para o desenvolvimento, aprendizagem, valorização dos saberes e culturas das crianças campesinas.

$\mathrm{Na}$ escola pesquisada os jogos e brincadeiras são trabalhados como estratégia metodológica e como conteúdo presente nas aulas de Educação Física. Os jogos e brincadeiras são trabalhados de formas sistemáticas e os professores compreendem a importância do conteúdo para o desenvolvimento integral da criança.

Nesse sentido, o estudo evidenciou que os jogos e brincadeiras são muito importantes e por isso precisam ser trabalhados na Educação Infantil de forma regular e sistemática, sabendo que o mesmo desenvolve na criança habilidades de raciocínio rápido, autonomia, criticidade, criatividade, responsabilidade e cooperação. Tal estratégia possibilita que as crianças se desenvolvam através das relações que elas mesmas vão estabelecer com os diferentes objetos, ambientes e sujeitos ali presentes.

\section{REFERÊNCIAS}

ANDRÉ, Marli E. D. A. e LUDKE, Menga. Pesquisa em Educação: Abordagens Qualitativas. São Paulo: EPU, 1986.

BRASIL. Lei n. 9.394 de 20 de dezembro de 1996. Estabelece as Diretrizes e Bases da Educação. Disponível em: http://www.planalto.gov.br/ccivil_03/leis/L9394.htm Acesso em: 05. maio. 2018.

CALDART, R. S. Educação do Campo:Notas para uma análise de percurso.

Trab.Educ.Saúde,Rio de Janeiro,v.7 n.1,p.35-64,mar./jun.2009

COLETIVO DE AUTORES. Metodologia do Ensino de Educação Física. São Paulo:

Cortez, 1992.

DARIDO, S. C.; RANGEL, I. C. A. Educação Física na Escola: Implicações para a prática pedagógica. São Paulo. Guanabara Koogan, 2005

FEIRA DE SANTANA. A SECRETARIA MUNICIPAL DE EDUCAÇÃO DE FEIRA DE SANTANA. Portaria 09/2017. Feira de Santana, 24 de Abril de 2017. Disponível em: $<$ http://www.feiradesantana.ba.gov.br/seduc/arq/portaria032016.pdf $>$ Acesso em: 17 de dez. de 2017.

FRIEDMANN, Adriana. Brincar: crescer e aprender - $O$ resgate do jogo infantil. São Paulo: Editora Moderna, 1996

SAVIANI, Demerval. A Pedagogia Histórico-Critica na Educação do Campo. In: Pedagogia histórico-crítica e educação no campo: história, desafios e perspectivas atuais. São Carlos: Pedro \& João Editores e Navegando, 2016. 305p 